\title{
KINERJA SUSUNAN DAN JUMLAH ELEMEN PELTIER PADA TEC ALAT TRANSPORTASI IKAN SEGAR
}

\section{Performance of Arrangement and Number the Peltier Elements on Refrigerated Fish Container TEC}

\author{
Tri Nugroho Widianto* dan Caesar Mahendra \\ Loka Riset Mekanisasi Pengolahan Hasil Perikanan, Jl. Imogiri Barat Km. 11,5, Yogyakarta, Indonesia \\ *Korespondensi Penulis: trinugrohowidianto@yahoo.com
}

Diterima: 21 November 2018; Direvisi: 12 Maret 2019; Disetujui: 12 Juni 2019

\begin{abstract}
ABSTRAK
Kinerja cara penyusunan dan jumlah elemen peltier pada pendingin termoelektrik (TEC) alat transportasi ikan segar telah diuji. TEC alat transportasi ikan segar terdiri dari komponen utama yaitu elemen peltier, heatsink, kipas, bracket alumunium dan heat pipe. Uji kinerja dilakukan terhadap susunan dan jumlah elemen peltier TEC alat transportasi ikan segar dengan variasi dua buah TEC dengan elemen peltier tunggal, dua buah TEC dengan elemen peltier ganda dan empat buah TEC dengan elemen peltier tunggal. Parameter yang diamati meliputi suhu ruang penyimpanan ikan, suhu heatsink dan kebutuhan energi TEC. Pengukuran dilakukan selama 120 menit dengan interval pengukuran setiap 10 menit. Suhu ruang peti penyimpanan ikan dengan dua buah TEC peltier ganda adalah $18,8^{\circ} \mathrm{C}$, dua buah TEC peltier tunggal sebesar 13,5 ${ }^{\circ} \mathrm{C}$ dan empat buah TEC peltier tunggal sebesar $8,5^{\circ} \mathrm{C}$. Kebutuhan energi TEC dengan dua buah elemen ganda sebesar 46 Watt, TEC dengan 2 buah elemen peltier tunggal sebesar 83 Watt, sedangkan pada 4 elemen peltier tunggal 166 Watt.
\end{abstract}

KATA KUNCI : pendingin termoelektrik, elemen peltier, ikan segar, penyimpanan ikan

\section{ABSTRACT}

Performance of arrangement and number of peltier elements on the refrigerated fish container TEC (thermoelectric cooler) had been tested. The TEC of refrigerated fish container was composed of peltier elements, a heatsink, a fan, an aluminum bracket, and a heat pipe. The arrangement and number of peltier element variations in each refrigerated container box were two TEC composed of a single peltier element, two TEC composed of dual peltier element and four TEC composed of a single peltier element. Performance test was conducted by measuring temperature of box container, temperature of heatsink, and the energy consumption of TEC. Performance test carried out at every 10 minutes for 120 minutes. Temperature of refrigerated container box composed of two TEC with dual peltier element was $18.8^{\circ} \mathrm{C}$, two TEC with single peltier element was $13.5^{\circ} \mathrm{C}$ and four TEC with single peltier element was $8.5^{\circ} \mathrm{C}$. The energy consumption of refrigerated container box of two TEC composed dual peltier element was 46 Watts, two TEC composed of single peltier element was 83 Watts and four TEC composed of single peltier element were 166 Watts.

KEYWORDS: thermoelectric cooler, peltier elements, fish container

\section{PENDAHULUAN}

Salah satu cara penanganan ikan segar selama penyimpanan dan transportasi yang dinilai baik adalah dengan pendinginan. Persyaratan BSN (2013) tentang penanganan ikan segar adalah menjaga suhu ikan tetap rendah di bawah $5^{\circ} \mathrm{C}$. Pada kondisi tersebut, mutu ikan dapat dipertahankan karena proses pembusukan ikan yang disebabkan oleh bakteri dan proses biokimia dapat diperlambat (Gelman, Glatman,
Drabkin, \& Harpaz, 2001; Wibowo \& Yunizal, 1998). Penyimpanan pada suhu tinggi dapat memacu pertumbuhan mikroba pembusuk, reaksi oksidasi dan aktivitas enzimatik (Kotta, Moeller, Orav-Kotta \& Paernoja, 2014; Pack et al., 2014). Selain penyimpanan ikan pada suhu rendah, cara mematikan dan penyiangan ikan yang baik juga dapat memperlama proses kemunduran mutu ikan (Munandar, Nurjanah \& Nurilmala, 2009). 
Penanganan ikan segar menggunakan es dinilai mudah dan murah untuk mempertahankan mutu ikan (Jain \& llyas, 2005). Selain es, metode pendinginan menggunakan sistem pendingin telah berkembang sejak dulu. Sistem pendingin umumnya menggunakan sistem kompresi uap (Aziz, 2009; Ginting, Aziz \& Kurniawan, 2014; Sulaiman \& Asriandi, 2016), namun untuk kapasitas pendinginan yang kecil yang cocok digunakan pedagang ikan keliling dapat menggunakan alternatif pendingin termoelektrik (TEC). Sistem pendingin TEC (Astrain, Martinez \& Rodriquez, 2013; Chen, Liao \& Hung, 2012; Meng, Wang \& Zhang, 2013; Zhang, Mui \& Tarin, 2010; Zhao \& Tan, 2014) menggunakan elemen peltier dengan sumber arus listrik DC. Salah satu alat yang dapat digunakan untuk mendistribusikan ikan segar oleh pedagang ikan keliling adalah Altis-2, yaitu alat transportasi ikan segar untuk kendaraan bermotor roda dua (sepeda motor). Altis-2 berbentuk peti untuk menyimpan ikan yang dilengkapi dengan pendingin seperti telah dikembangkan oleh Widianto, Hermawan \& Utomo (2014). Altis-2 dapat membantu dan memudahkan proses distribusi ikan segar oleh pedagang ikan dengan sepeda motor. Penggunaan Altis-2 tersebut dapat memudahkan transportasi dan mempertahankan suhu ikan tetap rendah. Hasil pengujian tingkat penerimaan pengguna terhadap Altis-2 menunjukkan bahwa salah satu faktor yang menentukan penerimaan pengguna adalah kemudahan pengoperasian alat, di mana salah satu yang perlu perbaikan adalah lebar atau ukuran Altis-2 (Hakim, Siregar, Widianto \& Purnomo, 2016).

Altis-2 (Gambar 1) dioperasikan dengan menggunakan sumber energi dari aki sepeda motor atau baterai tambahan. Namun, mengingat aki sepeda motor atau baterai tambahan mempunyai kapasitas sangat terbatas, maka optimasi pendingin TEC perlu dilakukan agar performansinya menjadi lebih baik dan kebutuhan energinya rendah. Optimasi yang telah dilakukan di antaranya adalah dengan pengaturan voltase yang berbeda untuk mengetahui kinerja pendingin TEC (Widianto \& Hakim, 2016). Selain itu, optimasi penggunaan jumlah elemen peltier serta cara penyusunannya juga perlu dilakukan agar didapatkan suhu peti yang rendah serta penggunaan energi listrik yang kecil. Mansur (2010) dan Sugiyanto (2008) telah melakukan penelitian yang menunjukkan hasil berbeda pada penggunaan elemen peltier untuk pendingin TEC pada peti insulasi. Pendingin termoelektrik menggunakan elemen peltier sebagai komponen utama dan arus listrik searah sebagai sumber energi serta beberapa komponen pendukung lainnya (Chein \& Chen, 2005; Karimi, Culham \& Kazerouni, 2011; Yu \& Wang, 2009; Zhou \& Yu, 2011). Tujuan penelitian ini untuk mempelajari performansi pendingin TEC dengan variasi jumlah elemen peltier dan cara penyusunan sehingga didapatkan performansi pendingin TEC dengan penggunaan energi rendah dan dapat diaplikasikan pada sepeda motor.

\section{BAHAN DAN METODE}

\section{Bahan Pengujian}

Pengujian Altis-2 dilakukan pada pendingin TEC yang tersusun oleh beberapa komponen utama seperti elemen peltier, heat pipe, heatsink, kipas, dudukan TEC dan komponen kelistrikan lainya. Pada pengukuran parameter pengujian digunakan multimeter, termometer digital dan sumber arus listrik

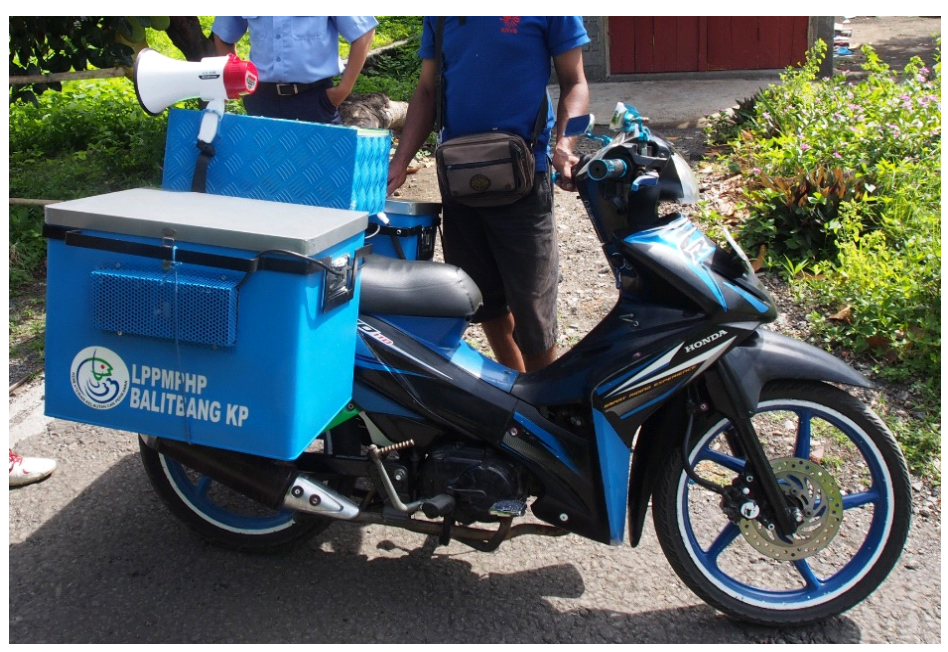

Gambar 1. Altis-2 untuk pedagang ikan keliling

Figure 1. Altis-2 for fish mobile retailer 
searah dengan menggunakan power supply arus searah tipe KXN 30200. Elemen peltier sebagai komponen utama pada penelitian ini digunakan tipe TEC1-12706 dengan spesifikasi ditunjukkan pada Tabel 1.

\section{Pembuatan Peti Penyimpanan Ikan}

Peti penyimpanan ikan pada Altis-2 dibuat berbentuk kotak persegi panjang dengan volume 33 L. Dinding peti tersusun dari lapisan luar dan lapisan dalam yang ditambahkan insulator di antara kedua dinding tersebut. Lapisan luar dan dalam dinding menggunakan bahan alumunium tebal $1 \mathrm{~mm}$. Sebagai insulator digunakan poliuretan tebal sekitar $33 \mathrm{~mm}$. TEC disusun pada dudukan yang terbuat dari papan kayu dengan ukuran panjang $50 \mathrm{~cm}$, lebar $20 \mathrm{~cm}$ dan tebal $2 \mathrm{~cm}$. TEC kemudian diletakkan pada bagian atas peti yang sebelumnya dilubangi dengan ukuran sesuai dudukan TEC. Gambar skema peti penyimpanan ikan beserta dudukan pendingin ditunjukkan pada Gambar 2.
Susunan Pendingin TEC diadopsi dari penelitian Widianto \& Hakim (2016) seperti ditunjukkan pada Gambar 3 terdiri dari beberapa komponen yaitu elemen peltier, heatpipe, heatsink, bracket alumunium dan kipas. Elemen peltier bekerja menggunakan arus listrik searah yang menyebabkan sisi elemen peltier menjadi dingin dan sisi lainya menjadi panas. Sisi dingin elemen peltier tersebut dimanfaatkan untuk memindahkan panas dari dalam ruang peti penyimpanan ikan sehingga ruang peti menjadi dingin. Sisi panas elemen peltierdipindahkan menuju lingkungan melelui heatpipe dengan penambahan kipas agar proses pelepasan panas menjadi lebih cepat. Proses penyerapan panas ruang peti menuju sisi dingin peltier dioptimalkan menggunakan heatsink dan kipas.

\section{Variasi Jumlah dan Penyusunan Peltier}

Variasi jumlah dan penyusunan elemen peltier pendingin TEC pada peti penyimpanan ikan terdiri dari tiga variasi yaitu dua buah pendingin TEC dengan elemen peltier tunggal, dua buah pendingin TEC

Tabel 1. Spesifikasi elemen peltier Table 1. Peltier module specifications

\begin{tabular}{lc}
\hline \multicolumn{1}{c}{ Spesifikasi/Specifications } & Nilai/Value \\
\hline Dimensi $(\mathrm{p} \times \mathrm{I} \times \mathrm{t}) /$ dimension $(I \times w \times t)$ & $(40 \times 40 \times 3.8) \mathrm{mm}$ \\
Energi maksimal/Maximum cooling power & $53 \mathrm{Watt}$ \\
Arus maksimal/Maximum current & $6.4 \mathrm{~A}$ \\
Perbedaan suhu maksimal/Maximum temperature difference & $68{ }^{\circ} \mathrm{C}$ \\
Hambatan/Resistance, $\mathrm{R}$ & $1.98 \mathrm{Ohm}$ \\
Luas area/Surface area & $1.6 \times 10^{-6} \mathrm{~m}^{2}$ \\
\hline
\end{tabular}

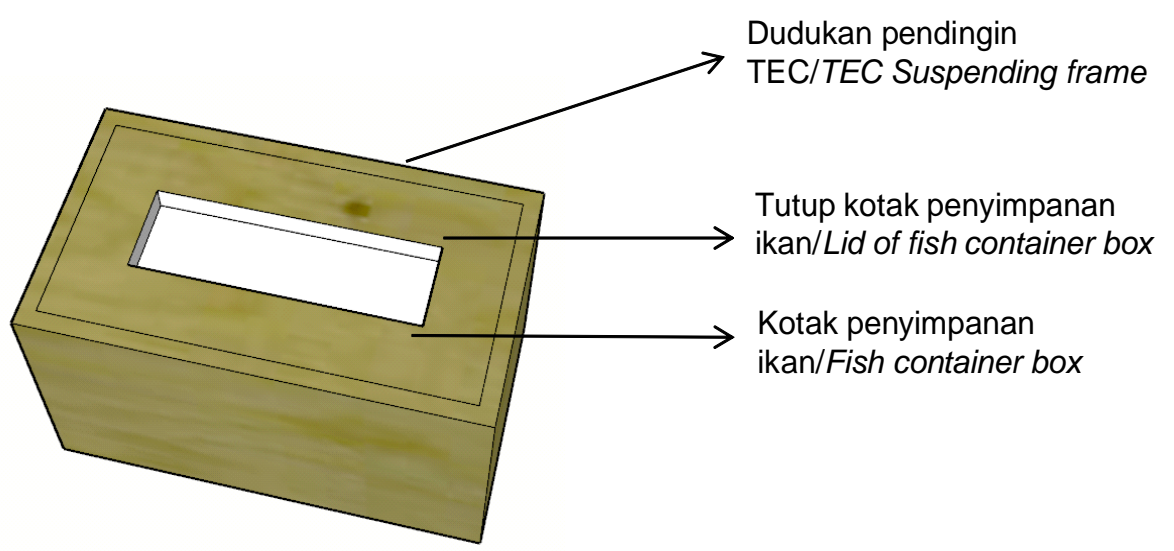

Gambar 2. Desain kotak penyimpanan ikan untuk pengujian performansi Figure 2. Fish container box design for performance test 
Tabel 2. Variasi jumlah dan penyusunan peltier pada TEC

Table 2. Variety of numbers and arrangement peltier on TEC

\begin{tabular}{lc}
\hline \multicolumn{1}{c}{ Variasi/Variety } & $\begin{array}{c}\text { Jumlah TEC/ } \\
\text { Numbers of TEC }\end{array}$ \\
\hline Dua elemen peltier tunggal/Two single peltier & 2 \\
Dua elemen peltier ganda/Two double peltier & 2 \\
Empat elemen peltier tunggal/Four single peltier & 4 \\
\hline
\end{tabular}

dengan elemen peltier ganda dan empat buah pendingin TEC dengan elemen peltier tunggal. Komposisi tiap variasi pendingin TEC ditunjukkan pada Tabel 2 . Setiap variasi pendingin TEC diletakkan di atas kotak penyimpanan ikan dengan posisi TEC ditunjukkan pada Gambar 4 dan Gambar 5. Ilustrasi elemen tunggal dan ganda ditunjukkan pada Gambar 6. Masing-masing elemen peltier dirangkai dengan komponen lainya berupa heatsink, bracket alumunium dan heatpipe sehingga membentuk unit pendingin TEC dengan penyusunan seperti pada Gambar 7.
Pengujian masing masing variasi pendingin TEC dilakukan tanpa beban menggunakan listrik searah (tegangan $12 \mathrm{~V}$ ) dengan tiga kali ulangan. Pengujian dilakukan dengan mengukur suhu heatsink dan ruang peti penyimpanan ikan menggunakan termometer digital tiap 10 menit selama 120 menit pengujian. Titiktitik pengukuran ditunjukkan pada Gambar 3. Selain suhu juga dilakukan pengukuran arus listrik yang melewati elemen peltier menggunakan multimeter. Pengukuran arus listrik digunakan untuk menghitung kebutuhan energi TEC pada tegangan $12 \mathrm{~V}$. Kebutuhan energi listrik TEC didapatkan dari hasil perkalian arus dengan tegangan yang melalui TEC.

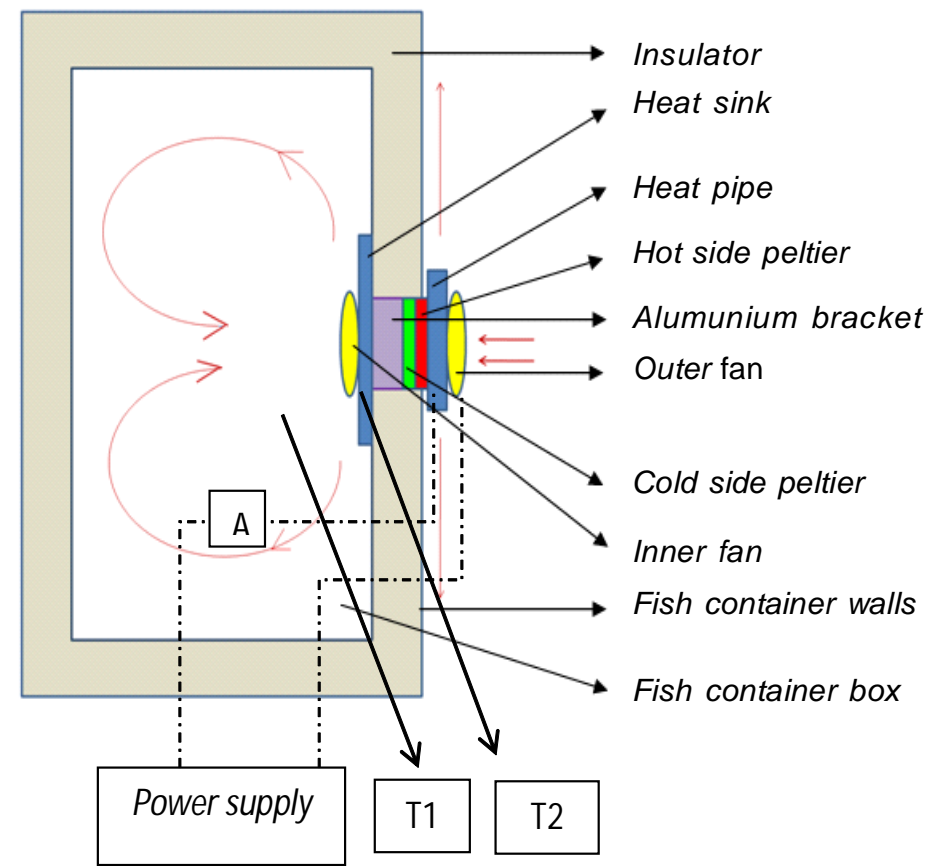

Keterangan/notes :

$\mathrm{A}=$ arus listrik/electric current

$\mathrm{T} 1$ = titik pengukuran suhu peti penyimpanan ikan/fish container temperature measurement point

T2 = titik pengukuran suhu heatsink/heatsink temperature measurement point

Gambar 3. Skema penyusunan pendingin TEC (Widianto \& Hakim, 2016)

Figure 3. TEC arrangement design (Widianto \& Hakim, 2016) 


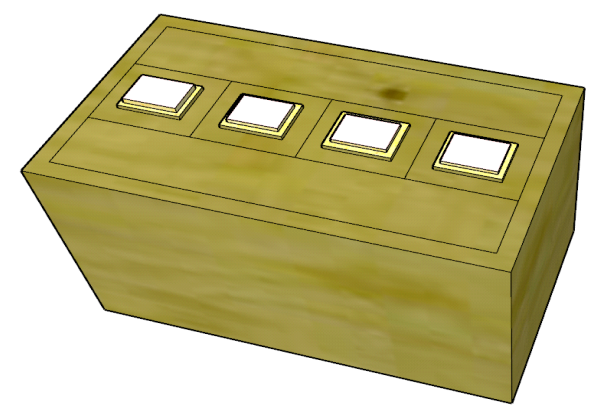

Gambar 4. Penyusunan empat buah pendingin TEC

Figure 4. Arrangement of four units TEC

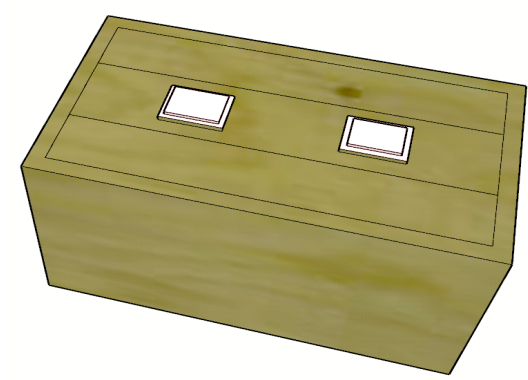

Gambar 5. Penyusunan dua buah pendingin TEC

Figure 5. Arrangement of two units TEC
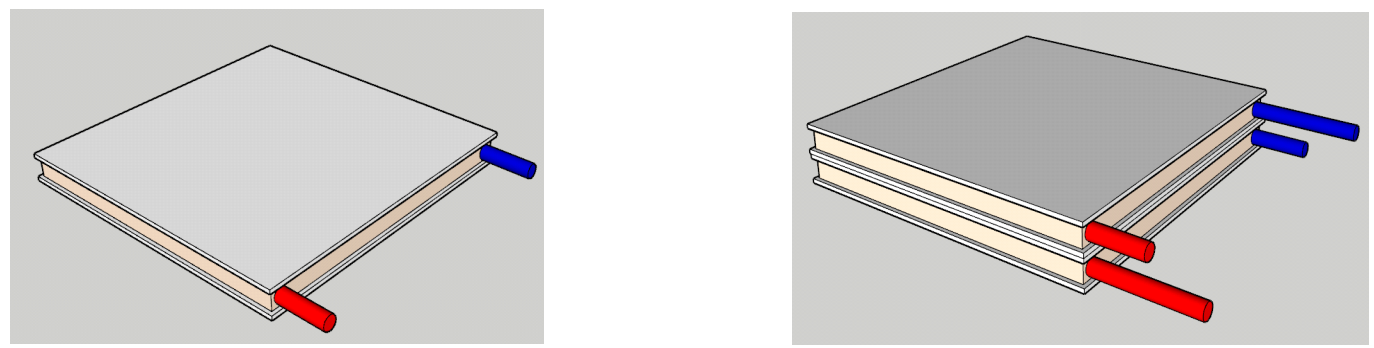

Gambar 6. Elemen peltier tunggal (a) dan ganda (b)

Figure 6. Single peltier (a) and double peltier (b)



Gambar 7. Penyusunan TEC

Figure 7. Arrangement of TEC 


\section{HASIL DAN PEMBAHASAN}

Hasil pengukuran suhu heatsink pada peti penyimpanan ikan ditunjukkan pada Gambar 8 . Suhu heatsink turun cepat pada 10 menit pertama pada penggunaan 4 buah elemen peltier tunggal dan dua buah elemen peltier tunggal, sedangkan pada dua buah elemen peltierganda penurunan suhu cenderung lambat sampai menit 70 kemudian konstan. Pada akhir pengujian capain suhu heatsink pada penggunaan 2 elemen ganda, dua elemen tunggal dan 4 elemen tunggal berturut-turut $17{ }^{\circ} \mathrm{C}, 9,7^{\circ} \mathrm{C}$ dan $2,1^{\circ} \mathrm{C}$.

Dari ketiga perlakuan menunjukkan bahwa penggunaan 4 buah TEC dengan elemen peltier tunggal menghasilkan capaian suhu yang paling rendah. Capaian suhu heatsink tiap-tiap pendingin TEC tergantung pada jumlah arus yang digunakan. Pada penelitian Abdul-Wahab et al. (2008) menunjukkan bahwa pada arus listrik yang maksimal didapatkan suhu sisi dingin elemen peltier yang rendah. Capaian suhu heatsink pada tiap TEC juga dipengaruhi volume ruang pendinginan serta jumlah TEC dalam ruang pendingin. Makin kecil volume peti mengakibatkan jumlah panas yang berpindah ke heatsink juga makin sedikit sehingga menghasilkan suhu heatsink yang rendah, sedangkan semakin banyak jumlah pendingin TEC mengakibatkan kapasitas pendinginan semakin bertambah. Perpindahan panas secara konveksi dapat terjadi karena adanya perbedaan suhu antara permukaan benda dengan fluida (Jiji, 2006). Hal ini yang menyebabkan adanya perpindahan panas dari ruang peti menuju heatsink akibat perbedaan suhu keduanya.

Pada elemen peltier tunggal, semakin banyak jumlah pendingin TEC akan semakin rendah capaian suhu ruang dan heatsink seperti ditunjukkan pada Gambar 8. Penggunaan 4 buah peltier tunggal menghasilkan kapasitas pendinginan yang lebih besar dibandingkan 2 buah peltier tunggal, sehingga panas ruang peti yang diserap oleh pendingin juga semakin besar akibatnya capaian suhu ruang menjadi lebih rendah. Adanya kipas yang membantu proses perpindahan panas secara konveksi paksa mengakibatkan capaian suhu heatsink tiap TEC mengikuti capaian suhu ruang sampai perbedaan suhu antara heatsink dan ruang menjadi konstan seperti ditunjukkan pada Gambar 9.

Pola yang sama juga ditunjukkan pada hasil pengukuran suhu ruang peti penyimpanan ikan seperti pada Gambar 8. Penurunan suhu ruang peti penyimpanan ikan diakibatkan oleh terjadinya penyerapan/transfer panas ruang peti oleh heatsink secara konveksi. Pada penggunaan 2 buah elemen peltier ganda, suhu ruang peti insulasi turun sampai $18,8^{\circ} \mathrm{C}$. Penggunaan 2 elemen peltier tunggal capaian suhunya lebih rendah mencapai $13,5^{\circ} \mathrm{C}$, sedangkan pada penggunaan 4 buah elemen peltier tunggal

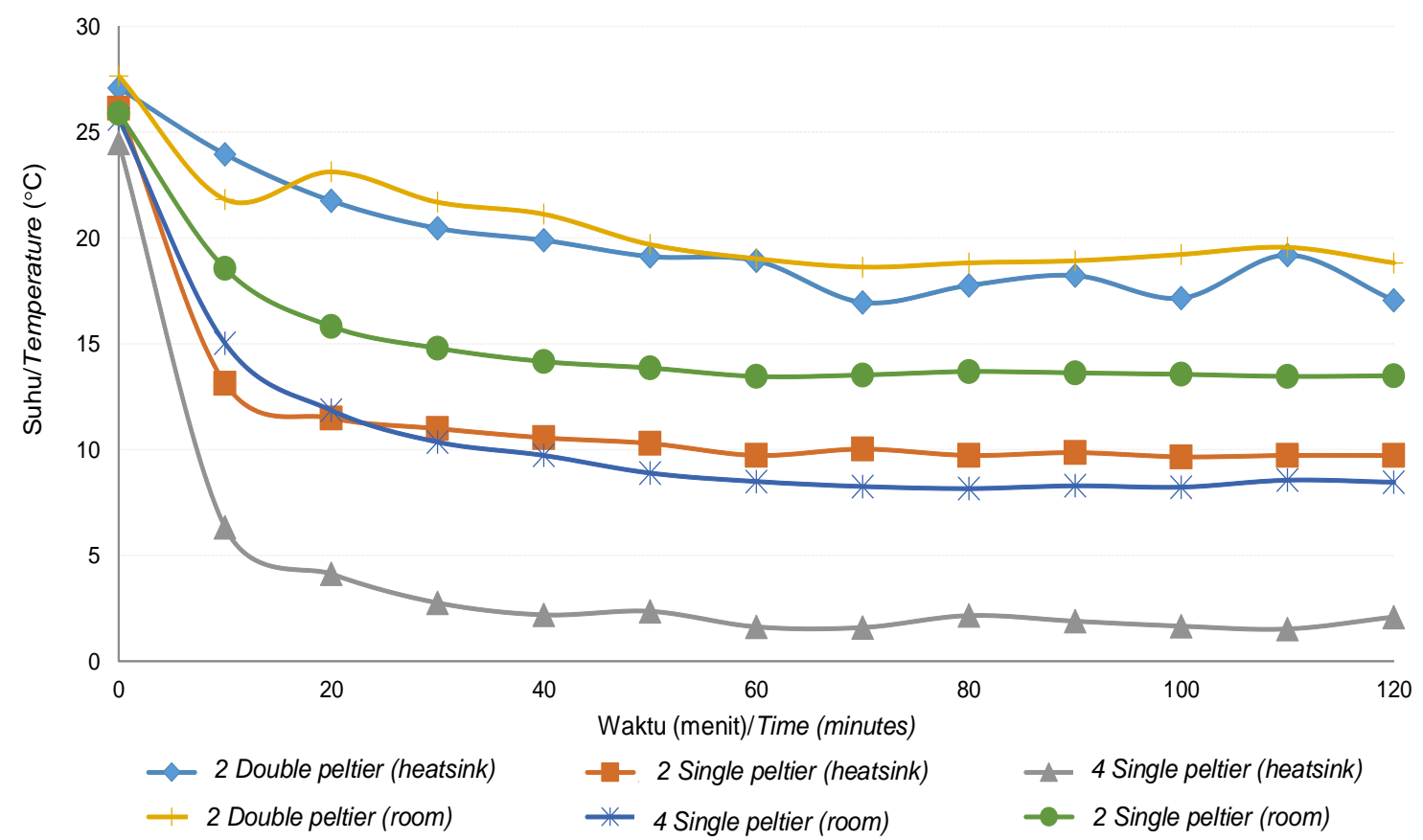

Gambar 8. Suhu heatsink dan ruang selama pengujian

Figure 8. Heatsink and room temperatures during performance test 


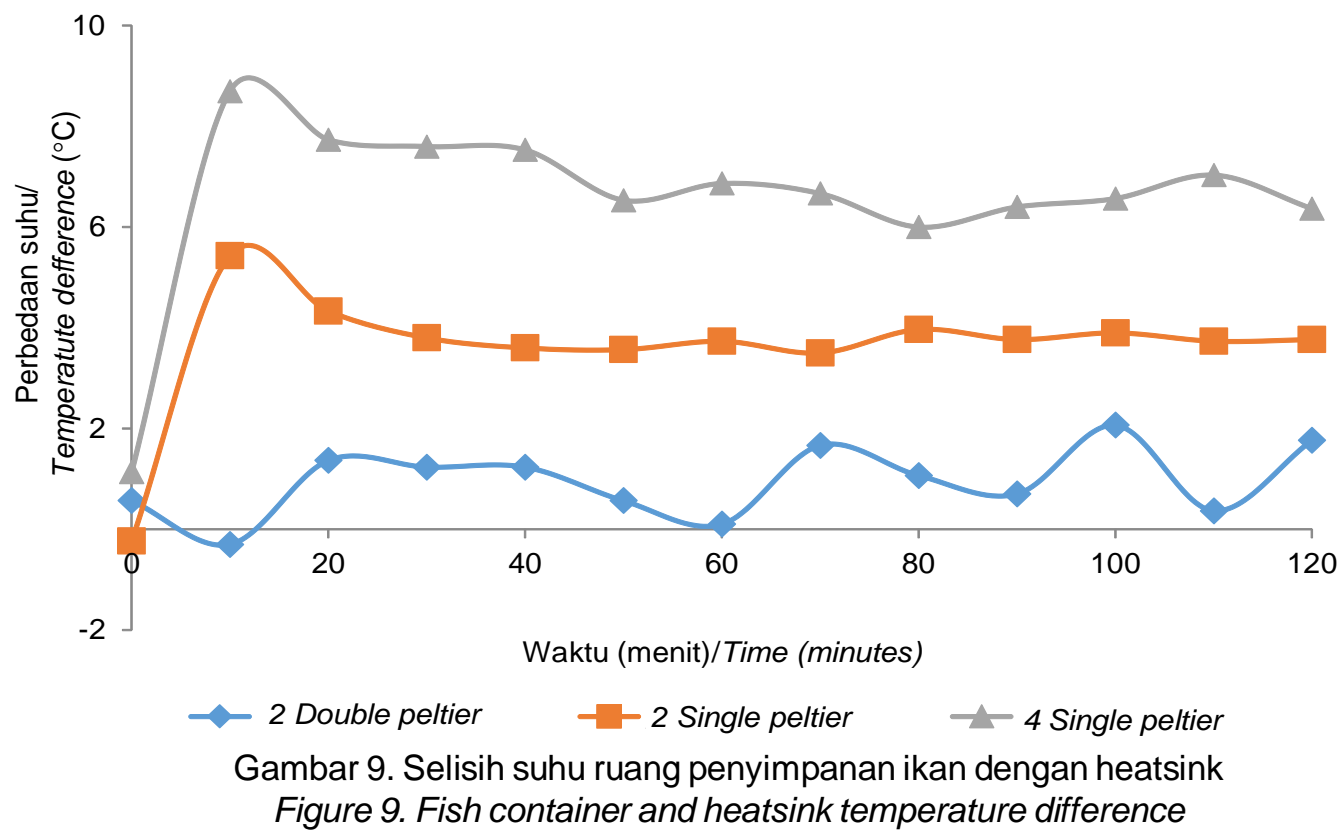

capaian suhunya paling rendah sebesar $8,4^{\circ} \mathrm{C}$. Semakin banyak jumlah pendingin TEC yang digunakan akan meningkatkan kapasitas pendinginan, sehingga panas ruang yang diserap oleh TEC semakin besar akibatnya suhu ruang akan semakin rendah. Hal ini yang menyebabkan capaian suhu ruang pada penggunaan 4 buah elemen peltier tunggal paling kecil. Pada jumlah TEC yang sama, penggunaan elemen peltiertunggal diperoleh capaian suhu yang lebih rendah dibandingkan dengan elemen peltier ganda. Hal tersebut disebabkan oleh

banyaknya arus listrik yang melalui elemen peltier. Banyaknya arus listrik yang melalui elemen peltier ganda lebih sedikit dibandingkan pada elemen peltier tunggal, sehingga panas yang dipindahkan juga akan semakin kecil. Penyusunan kelistrikan pada elemen peltier ganda dilakukan secara seri agar diperoleh jumlah arus listrik yang melalui elemen peltier lebih optimal.

Selisih suhu heatsink dengan ruang tempat penyimpanan ikan pada berbagai perlakuan juga

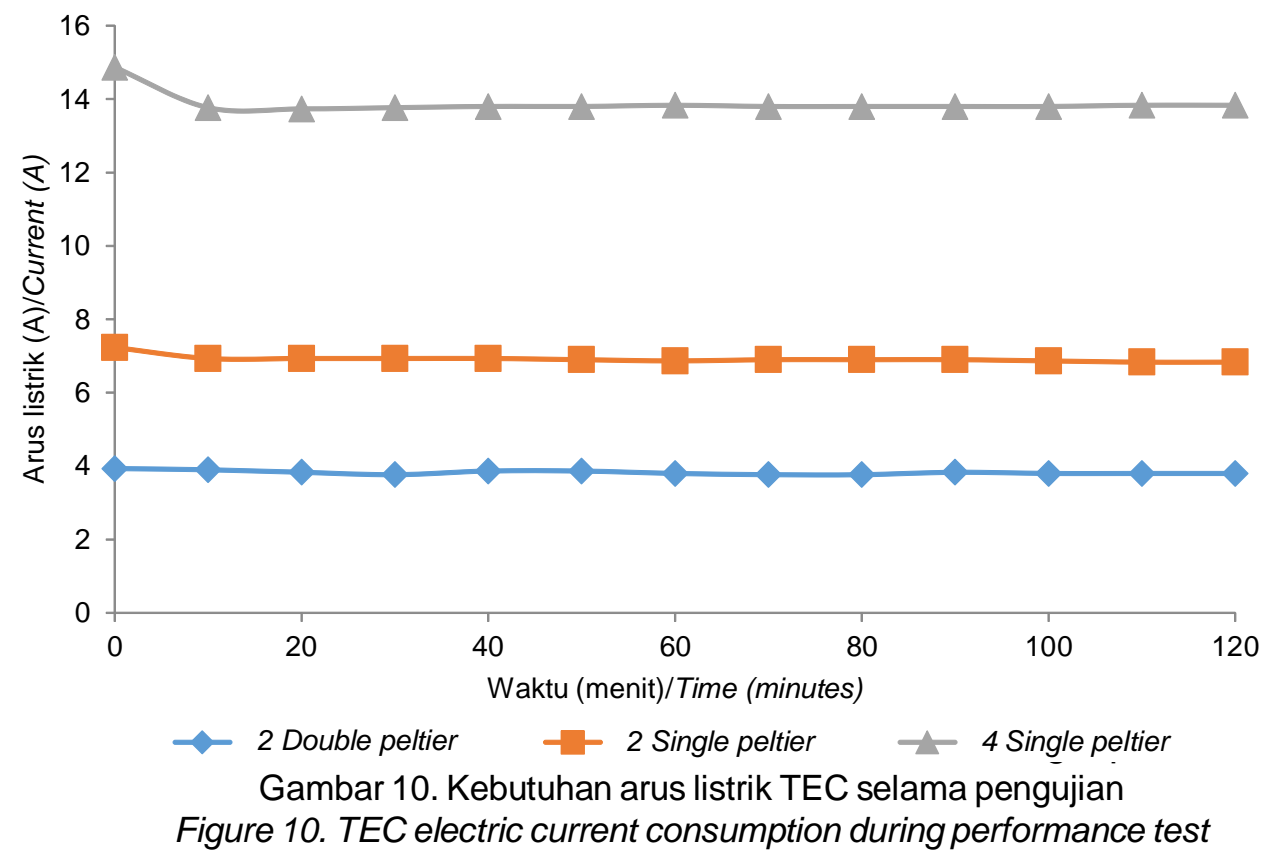


berbeda-beda (Gambar 9). Selisih capain suhu ruang dengan heatsink pada penggunaan dua elemen ganda rata-rata sebesar $0,9^{\circ} \mathrm{C}$, sedangkan pada dua elemen tunggal sebesar $3,6^{\circ} \mathrm{C}$. Pada penggunaan 4 buah elemen peltiertunggal didapatkan selisih capaian suhu heatsink dengan ruang penyimpanan ikan paling besar yaitu $6,5^{\circ} \mathrm{C}$. Sehingga pada penggunaan 4 buah pendingin TEC, sebaiknya digunakan spesifikasi kipas dengan aliran udara yang lebih tinggi agar dapat membantu proses konveksi perpindahan panas dari udara menuju heatsink.

Hasil pengukuran kebutuhan arus listrik selama pengujian ditunjukkan pada Gambar 10. TEC dengan menggunakan elemen peltiertunggal, kebutuhan arus total sebanding dengan jumlah peltier yang dipergunakan. Penggunaan elemen peltierganda pada jumlah TEC yang sama dapat mengurangi kebutuhan arus listrik jika dibandingkan dengan peltier tunggal. Kebutuhan arus listrik pada penggunaan peltierganda membutuhkan arus sebesar 1,9 A tiap elemen peltier (3,8 A untuk 2 TEC), sedangkan pada peltier tunggal membutuhkan arus sebanyak 3,44 A tiap elemen peltier (6,9 A untuk 2 TEC). Dengan demikian salah satu cara untuk mengurangi kebutuhan arus pada TEC adalah dengan menggunakan elemen peltier ganda yang dirakit secara parallel dan perakitan kelistrikan secara seri seperti disampaikan oleh Sugiyanto (2008). Tujuan perakitan parallel elemen peltier agar diperoleh perbedaan suhu yang tinggi antara kedua sisi elemen peltier, sehingga kalor yang dilepas semakin besar. Penyusunan kelistrikan secara seri agar diperoleh jumlah arus listrik yang melalui elemen peltier lebih optimal (Widianto, 2013).
Hasil pengukuran dan perhitungan kebutuhan energi Altis-2 pada berbagai perlakuan ditunjukkan pada Gambar 11. Kebutuhan energi pada dua buah elemen ganda sebesar 46 Watt, dua buah elemen tunggal sebesar 83 Watt, sedangkan empat buah elemen tunggal sebesar 166 Watt. Pada penggunaan 4 buah elemen peltier tunggal membutuhkan energi 2 kali lipat dibanding dengan 2 buah elemen peltier tunggal. Sedangkan penggunaan 2 elemen ganda membutuhkan energi yang paling kecil. Pada prakteknya pemilihan jumlah elemen peltier sangat tergantung dari ketersedian dan spesifikasi sumber energi serta kebutuhan beban pendinginan. Sumber energi pada sepeda motor yang digunakan oleh pedagang ikan keliling sangat terbatas, sehingga penggunaan jumlah dan susunan peltier dalam TEC perlu mempertimbangkan spesifikasi aki sepeda motor. Beban pendinginan dipengaruhi oleh lamanya proses penjualan ikan, jumlah ikan dan kondisi ikan sebelum dibawa. Sepeda motor yang digunakan oleh masyarakat umumnya menggunakan aki kapasitas 3,5- $6 \mathrm{hA}$, sehingga untuk aplikasi Altis-2, susunan dua buah elemen ganda lebih tepat karena membutuhkan energi yang paling rendah. Namun demikian penggunaan aki tambahan atau aki khusus untuk kebutuhan ALtis-2 lebih disarankan agar ketercukupan energi TEC lebih baik.

\section{KESIMPULAN}

Capaian suhu ruang peti penyimpanan ikan dengan dua buah elemen peltier ganda sebesar 18,8 ${ }^{\circ} \mathrm{C}$, dua buah elemen peltier tunggal sebesar $13,5^{\circ} \mathrm{C}$



Gambar 11. Kebutuhan energi TEC selama pengujian Figure 11. TEC energy consumption during performance test 
dan empat buah elemen tunggal sebesar $8,5^{\circ} \mathrm{C}$. Kebutuhan energi terendah adalah TEC dengan dua buah elemen ganda sebesar 46 Watt dan tertinggi pada 4 buah elemen peltier tunggal sebesar 166 Watt, sedangkan pada 2 elemen peltier tunggal 83 Watt. Susunan dua buah elemen ganda lebih tepat digunakan pada Altis-2 karena membutuhkan energi yang paling rendah serta sesuai dengan spesifikasi aki sepeda motor.

\section{UCAPAN TERIMAKASIH}

Tulisan ini merupakan hasil penelitian Pengembangan Prototipe Peti Insulasi untuk Produk Perikanan T.A. 2014 dan 2016, di Loka Riset Mekanisasi Pengolahan Hasil Perikanan, Bantul. Kontributor utama pada penelitian ini adalah Tri Nugroho Widianto, sedangkan kontributor anggota adalah Caesar Mahendra. Diucapkan terima kasih kepada semua peneliti yang terlibat dalam pelaksanaan kegiatan penelitian.

\section{DAFTAR PUSTAKA}

Abdul-Wahab, S. A., Elkamel, A., Al-Damkhi, A. M., AlHabsi, I. A., Al-Rubai'ey', H. S., Al-Battashi, A. K., AlTamimi, A. R., Al-Mamari, K. H., \& Chutani, M. U. (2009). Design and experimental investigations of portable solar thermoelectric referigerator. Renewable Energy, 34, 30-34.

Astrain, D., Martinez, A., \& Rodriquez, A. (2013). Improvement of a thermoelectric and vapour compression hybrid referigerator. Apllied Thermal Engineering, 39, 140-150

Aziz, A. (2009). Studi eksperimental mesin refrigerasi siklus kompresi uap menggunakan refrigeran hidrokarbon substitusi R22 pada kondisi transient. Jurnal Teknik Mesin, 6(2), 75-78.

BSN (2013). Ikan Segar SNI 2729-2013. Badan Standardisasi Nasional.

Chein, R. \& Chen, Y. (2005). Performances of thermoelectric cooler Integrated with microchannel heatsinks. International Journal of Refrigeration. 28, 828-839.

Chen, W. H., Liao, C. Y., \& Hung, C. I. (2012). A numerical study on the performance of miniature thermoelectric cooler effected by thomson effect. Applied Energy, 89, 464-473

Gelman, A., Glatman, L., Drabkin, V., \& Harpaz, S. (2001). Effect of storage temperature and preservative treatment on shelf life of the pond-raised freshwater fish, silver perch (Bidyanus bidyanus). Journal Food Protection, 64, 1584-1591.

Ginting, H., Aziz, A., \& Kurniawan, I. (2014). Temperatur sistem pendingin siklus kompresi uap terhadap perubahan beban pendinginan dengan penambahan kondensor dummy Sebagai water heater. Jom FTeknik, 1(2), 1-6.
Hakim, A. R., Siregar, Z., Widianto, T. N., \& Purnomo, A. H. (2016). Analisis peneriaman alat transportasi ikan segar berpendingin menggunakan pendekatan technology appcetance models. Jurnal Pascapanen dan Bioteknologi Kelautan dan Perikanan, 11(1), 1324.

Jain, D. \& Ilyas, S. M. (2005). Development of mathematical model for cooling. Journal of Food Engineering, 71 (25).

Jiji, L. M. (2006). Heat convection. Newyork. Spriger

Karimi, G., Culham, J. R., \& Kazerouni, V. (2011). Performance analysis of multi stage thermoelectric coolers. International Journal of Refrigeration, 34, 2129-2135.

Kotta, J., Moeller, T., Orav-Kotta, H., \& Paernoja, M. (2014). Realized niche width of brackish water submerged aquatic vegetation under current enviromental conditions and projected influences of climate change. Marine enviromental research, 102, 88-101

Mansur. (2010). Pengembangan Peti Insulasi Tipe CB02 Multifungsi Ramah Lingkungan Berbasis Termoelektrik untuk Kendaraan Roda Dua. Universitas Indonesia.

Meng, J. H., Wang, X. D., \& Zhang, X. X. (2013). Transient modeling and dynamic characteristics of thermoelectric cooler. Applied Energy, 108, 340-348.

Munandar, A., Nurjanah, \& Nurilmala, M. (2009). Kemunduran mutu ikan nila (oreochromis niloticus) pada penyimpanan suhu rendah dengan perlakuan cara kematian dan penyiangan. Jurnal Teknologi Pengolahan Hasil Perikanan Indonesia, 11(2), 88101.

Pack, E. C., Lee, S. H., Kim, C. H., Lim, C. H., Sung, D. G., Kim, M. H., \& Kim, S. W. (2014). Effects of enviromental temperature change og mercury absopstions in aquatic organism with respect to climate warming. Journal of Toxicology and Enviromental Health-Part A-Current Issues, 77 (22-24), 1477-1490.

Sulaiman \& Asriandi, D. (2016). Pengembangan sistem pendingin ejector untuk pendinginan vakum produk sayuran-sayuran. Jurnal Teknik Mesin Institut Teknologi Padang, 6(2), 92-97.

Sugiyanto. (2008). Pengembangan peti insulasi sepeda motor berbasis termoelektrik dan heat pipe. Universitas Indonesia.

Wibowo, S. \& Yunizal. (1998). Penanganan Ikan Segar. Badan Litbang Pertanian. Jakarta.

Widianto, T. N., Hermawan, W., \& Utomo, B. S. B. (2014). Uji coba peti ikan segar berpendingin untuk pedagang ikan keliling. Jurnal Pascapanen dan Bioteknologi Kelautan dan Perikanan, 9(2), 185-191

Widianto, T. N. \& Hakim, A. R. (2016). Performansi pendingin termoelektrik alat transportasi ikan segar pada berbagai tegangan. Agritech, 36(4), 485-490.

Widianto, T. N. (2013). Desain alat transportasi ikan segar berpendingin untuk pedagang ikan keliling. Institut Pertanian Bogor.

Yu, J. \& Wang, B .(2009). Enhancing the maximum coefficient of performance of themoelectric cooling modules using internally cascaded thermoelectric 
couples. International Journal of Refrigeration, 32, 32-39.

Zhou, Y. \& Yu, J. (2011). Design optimization of thermoelectric cooling systems for applications in electronic devices. International Journal of Refrigeration, 35, 1139-1144.
Zhao, D. \& Tan, G (2014). A riview of thermolectric cooling : materials, modeling and applications. Applied Thermal Engineering, 66, 15-24.

Zhang, H. Y., Mui, Y.C., \& Tarin, M. (2010). Analysis of thermoelectric cooler performance for high power electronic pagkages. Applied Thermal Engineering, 30, 561-568. 